\title{
PEMBUATAN DAN PENGUJIAN KUALITAS KOMPOS DI SUBAK TIBUBIYU KECAMATAN KERAMBITAN KABUPATEN TABANAN
}

\author{
I.W. Narka ${ }^{1}$, I.N. Dibia ${ }^{2}$, T. Kusmawati ${ }^{3}$, I.W.D. Atmaja ${ }^{4}$
}

\begin{abstract}
ABSTRAK
Pengabdian berupa pelatihan pembuatan kompos dengan bahan yang ada di sekitar petani memakai 3 bahan starter yaitu: EM4, MOL dan Nitrobakter TJ telah dilakukan di subak Tibubiyu, kecamatan Kerambitan Tabanan. Setelah pembuatan kompos selanjutnya adalah pengujian kualitas ketiga jenis kompos yang dihasilkan. Topik pembuatan kompos dan pengujian kualitas kompos ini dipilih berdasarkan permintaan petani karena disinyalir oleh petani pupuk organik kemasan yang didapatkan berupa bantuan, kualitasnya kurang baik. Merupakan masalah juga dalam hal pengangkutan ke areal pertanaman. Oleh karena itu perlu membuat kompos dekat areal pertanaman petani. Dalam meningkatkan kualitas kompos telah dicoba membuat kompos dengan 3 jenis starter dan selanjutnya dilakukan pengujian kualitas kompos. Petani menyambut baik kegiatan ini dan sangat antusias ingin mengetahui jenis starter yang mana yang terbaik hasil komposnya. Setelah fermentasi selama 6 minggu kompos telah matang, selanjutnya dilakukan pengujian kualitas kompos, Hasil pengujian kompos di laboratorium menunjukkan bahwa kualitas kompos yang paling adalah kompos dengan starter EM4. Dengan keberhasilan petani membuat sendiri pupuk kompos yang kualitasnya baik, maka percepatan penggunaan pupuk organik akan bisa dilakukan. Penggunaan pupuk kompos dapat mengurangi penggunaan pupuk kimia dan dan menjaga kelestarian tanah.
\end{abstract}

Kata Kunci: pupuk kompos. EM4, Mol, Nitrobacter.

\begin{abstract}
Devotion in the form of training of composting with existing materials around the farmers using 3 starter that is EM4, MOL and Nitrobacter TJ has been done in Subak Tibubiyu, Kerambitan Tabanan. After subsequent composting is testing the quality of the three types of compost produced. The topic of composting and compost quality testing is selected based on the farmers' demand because it is pointed out by the organic fertilizer farmers that the packaging is obtained in the form of aid, the quality is not good. Is a problem also in terms of transport to the planting area? Therefore, it is necessary to make compost near the farmer's cultivation area. In improving the quality of compost has been tried to make compost with 3 types of starter and then done the quality of compost testing. Farmers welcomed this activity and were interested to find out which type of starter was best composted. After fermentation for 6 weeks the compost has matured, then the quality of the compost is tested. The results of compost testing in the laboratory show that the best compost quality is compost with EM4 starter. With the success of farmers to make their own good quality compost fertilizer, the acceleration of organic fertilizer will be done. The use of compost fertilizer can reduce the use of chemical fertilizers and maintain the sustainability of the soil.
\end{abstract}

Keywords: compost fertilizer. EM4, Mol, Nitrobacter.

1,2,3,4,Staf Pengajar Program Studi Agroekoteknologi Fakultas Pertanian Universitas Udayana, wayannarka@gmail.com 


\section{PENDAhUluan}

Desa Tibubiyu termasuk dalam desa Dampingan, terletak di Kecamatan Kerambitan dimana kegiatan pertanian sangat intensif dengan pola tanam di Subak Tibubiyu padi - palawija. Pemaikaian pupuk organic masih sulit di tingkat petani, diperlukan dalam jumlah besar, masalah pengangkutan dan penggunaan, terlebih kalau pupuk organic didatangkan dari tempat yang cukup jauh dari lahan usahanya (Suriadikerta dan Setyorini, 2005). Dalam percepatan penggunaan pupuk organic di tanah sawah Subak Tibubiyu, perlu digalakkan pembuatan pupuk kompos oleh petani sendiri, sehingga masalah pengangkutan tidak menjadi kendala.

Pada saat diskusi dalam acara pengabdian tahun 2016 disinyalir oleh petani mutu kompos yang didapat dari bantuan, mutunya rendah, tanaman tidak menunjukkan respon (Narka, dkk., 2016). Hal ini mungkin disebabkan pupuk kompos yang diberikan sebagai bantuan belum matang, proses pengomposan belum selesai atau mutu bahan dasar kompos kurang baik. Oleh karena itu, petani meminta agar diberikan cara membuat kompos yang bermutu baik, mereka berkeinginan membuat kompos sendiri dengan mutu yang lebih baik, dengan menggunakan bahan jerami, sampah dan kotoran ternak yang ada di sekitar mereka.

Mutu kompos dipengaruhi oleh bahan dasar kompos dan starter kompos (activator kompos) yang digunakan (Mulyadi (2008). Nitrobakter TJ merupakan fermentor (activator) terbaik dibandingkan semua activator dalam permentasi bahan organic sehingga didapatkan pupuk kompos dalam waktu cepat dengan mutu yang baik (Janardi, 2015). Demikian juga EM4 dapat mempercepat proses pengomposan dengan konsentrasi pemberian $0,5 \%$ (Juniwati, 2012). Dalam menilai kualitas kompos akan dilakukan dengan menganalisis kadar hara kompos dan $\mathrm{C} / \mathrm{N}$ ratio. Mulyadi (2008) menyebutkan beberapa parameter penting dalam menilai kualitas kompos adalah $\mathrm{C} / \mathrm{N}$ ratio dan kandungan hara seperti nitrogen, fosfor, kalium dan calcium.

Pupuk organic (kompos) sangat penting dalam mempertahankan kesuburan tanah. Salah satu cara yang dapat dilakukan dalam menggalakkan penggunaan pupuk organic adalah dengan membuat sendiri Hasil penelitian tentang pemberian pupuk organik dan pupuk kimia yang dilakukan di Baturiti Tabanan menunjukkan bahwa pemberian pupuk kimia dapat menurunkan kualitas tanah, sementara kombinasi pupuk kimia dan pupuk organik dapat memperbaiki kualitas tanah setelah 5 tahun (Sardiana, 2015). Santi (2006) melaporkan bahwa pemberian pupuk kompos berpengaruh sangat nyata terhadap pertumbuhan tanaman tomat. Penelitian yang hampir sama yaitu tentang pengaruh pemberian pupuk organik dan pupuk anorganik terhadap pertumbuhan dan hasil tanaman padi telah dipublikasikan di jurnal Agrivigor. Fakultas Pertanian dan Kehutanan Unhas. Makasar. (Arafah, 2005).

\section{METODE PELAKSANAAN}

Masalah yang dihadapi oleh kelompok tani (anggota subak) telah dipecahkan dengan cara mengumpulkan pemuka masyarakat dan anggota subak (kelompok tani), kemudian akan diberikan penyuluhan dan pelatihan pembuatan kompos. Adapun prosedur pembuatan kompos yang akan dilakukan adalah sebagai berikut :

1. Langkah pertama siapkan box kayu untuk pengomposan. Perlu di perhatikan untuk desain baknya dengan ukuran $2.5 \times 1 \times 1 \mathrm{~m}$ dan pada dasar bak diberi alas karung atau terpal.

2. Selanjutnya campur semua bahan diatas ke dalam box pengomposan lalu aduk hingga merata. Kemudian diberikan activator nitrobakter. Pada box yang lain diberikan starter (activator) EM4 dan pada box yang ketiga diberikan starter Mol (mikroorganisme local).

3. Setelah itu tutup bagian atas bak pengomposan menggunakan plastik transaparan, hal ini juga berfungsi untuk menampung nitrogen yang di hasilkan dari proses pengomposan. Setelah kira2 4-5 hari siramkan hasil tampungan nitrogen tadi, hal ini di maksudkan untuk 
menambah kandungan nitrogen pada adonan bahan agar proses pengomposan bisa lebih cepat.

4. Lakukan step 3 hingga 2 atau 3 minggu secara rutin, setelah itu aduk kembali adonan agar merata dan ulangi step 3 lagi.

5. Terus lakukan step diatas hingga kira2 2-3 bulan agar adonan benar-benar matang, dalam step ini pupuk seharusnya sedikit berair.

6. Setelah 2-3 bulan, angkatlah adonan karena pupuk kompos sudah jadi, dan lakukanlah pengeringan dengan cara menjemur kompos hingga kadar airnya kira-kira $50-60 \%$ saja

7. Melakukan uji kualitas kompos meliputi kadar hara nitrogen, fosfor kalium dan kalsium serta $\mathrm{C} / \mathrm{N}$ rasio

Untuk meningkatkan gairah petani, bantuan berupa bahan starter (activator kompos) berupa nitrobakter, EM4 dan Mol telah diberikan. Di samping dalam bentuk pelatihan pembuatan kompos juga dilakukan pendampingan dalam pembuatan kompos bermutu baik.

\section{HASIL DAN PEMBAHASAN}

Pelaksanaan kegiatan Pembuatan dan Pengujian Kualitas Kompos di Subak Tibubiyu Kecamatan Kerambitan Kabupaten Tabanan selama (6 bulan) terhitung mulai persiapan, pelaksanaan dan pelaporan. Sampai akhir kegiatan ini telah dilakukan kegiatan persiapan berupa penjajagan lokasi ke Subak Tibubiyu, penyampaian dan konfirmasi kepada Kelian Subak. Kelian subak dan beberapa anggota subak menyambut baik kegiatan ini. Kegiatan selanjutnya yang telah dilaksanakan adalah penyuluhan kepada kelompok tani dan pembuatan kompos bersama petani. Petani sangat antusias dengan adanya kegiatan ini. Mereka akan mencoba membuat pupuk organic dengan bahan bahan yang ada di sekitar mereka. Mereka telah mencoba menggunakan tiga jenis starter yaitu nitrobakter, EM4 dan Mol. Mereka penasaran menunggu jenis atarter mana yang menghasilkan kompos dengan kualitas baik.

Monitoring berupa pengamatan hasil kompos juga telah dilakukan. Hasil kompos setelah dilakukan fermentasi sudah diambil kurang lebih $1 \mathrm{~kg}$ untuk dianalisis. Selanjutnya adalah dilakukan analisis kualitas kompos di laboratorium. Kegiatan ini agak terlambat pelaksanaannya. Penyuluhan baru bisa dilaksanakan 30 September 2017 yang disebabkan oleh terlambatnya pencairan dana. Analisis kualitas kompos dilaboratorium dilakukan dengan menganalisis kandungan hara seperti : nitrogen, Phosfor dan kalium dan $\mathrm{C} / \mathrm{N}$ rasio. Hasil analisis ketiga jenis kompos yang dihasilkan dcamtumkan pada Table 3.1.

Tabel 3.1. Kandungan hara dan $\mathrm{C} / \mathrm{N}$ ratio kompos yang dihasilkan

\begin{tabular}{|l|l|l|l|r|r|c|}
\hline No. & Starter kompos & $\begin{array}{l}\text { Kadar N } \\
(\mathbf{\%})\end{array}$ & $\begin{array}{l}\text { Kadar P } \\
(\mathbf{\%})\end{array}$ & $\begin{array}{l}\text { Kadar K } \\
(\mathbf{\%})\end{array}$ & $\begin{array}{l}\text { C-organik } \\
\mathbf{( \% )}\end{array}$ & C/N ratio \\
\hline 1 & EM4 & 1,68 & 2,28 & 1,78 & 27,83 & 16,57 \\
\hline 2 & Nitrobacter & 1,82 & 1,98 & 1,69 & 32,78 & 18,01 \\
\hline 3 & Mol & 1,49 & 2,14 & 1,52 & 35,89 & 24,09 \\
\hline
\end{tabular}

Berdasarkan hasil analisis pada Table 3.1 terlihat bahwa $\mathrm{C} / \mathrm{N}$ rasio terendah adalah pada kompos dengan starter EM4 yang berarti proses pengomposan telah berlangsung lebih cepat dibandingkan dengan starter lainnya. Jika diperhatikan dari kandungan hara $\mathrm{P}$, dan $\mathrm{K}$, juga terlihat bahwa kompos dengan starter EM4 yang tertinggi. Kompos dengan starter nitrobakter kandungan hara $\mathrm{N}$ juga tinggi, tetapi kandungan hara $\mathrm{P}$ dan $\mathrm{K}$ lebih rendah dan $\mathrm{C} / \mathrm{N}$ ratio tinggi. $\mathrm{C} / \mathrm{N}$ ratio menunjukkan kematangan kompos, dimana semakin kecil $\mathrm{C} / \mathrm{N}$ ratio semakin matang kompos. Mulyadi (2008) menyebutkan beberapa parameter penting dalam menilai kualitas kompos adalah $\mathrm{C} / \mathrm{N}$ ratio dan kandungan hara seperti nitrogen, fosfor, kalium dan calcium. Berdasarkan hasil analisis pada Tabel 3.1 maka dapat disimpulkan bahwa starter yang paling baik adalah EM4, 
kemudian disusul oleh kompos dengan starter nitrobakter dan terakhir adalah kompos dengan starter mol.

\section{KESIMPULAN DAN SARAN}

Berdasarkan kegiatan yang telah dilakukan dapat disimpulkan beberapa hal sebagai berikut :

1. Telah dilakukan penjajagan lokasi, konfirmasi kegiatan pengabdian, dan penyuluhan pembuatan pupuk kompos dengan menggunakan tiga jenis starter.

2. Petani sangat antusias dan menyambut baik kegiatan ini karena sangat bermanfaat dan dapat menghasilkan pupuk organic yang bermutu baik. Hal ini sangat penting untuk menjaga kesuburan tanah sawah, mereka mau bertani secara organic, menghasilkan beras organic

3. Hasil pengujian kualitas kompos menunjukkan bahwa kompos terbaik adalah kompos dengan starter EM4

4. Pendampingan pembuatan pupuk organic agar dapat bertani secara organic akan terus dilakukan.

5. Rencana selanjutnya adalah penerapan ketiga jenis kompos yang dihasilkan petani dan pembuatan pestisida organik.

Pelaksanaan kegiatan pada tahun ini agak terlambat karena keterlambatan cairnya dana. Oleh karena itu, disarankan kegiatan pengabdian kepada masyarakat selanjutnya pada tahun mendatang agar diberikan waktu yang cukup dari keluarnya dana sampai pembuatan laporan.

\section{UCAPAN TERIMAKASIH}

Penulis mengucapkan terima kasih kepada Lembaga Penelitian dan Pengabdian kepada Masyarakat Universitas Udayana atas dana yang telah diberikan sehingga kegiatan hibah Udayana Mengabdi dapat dilaksanakan dengan baik.

\section{DAFTAR PUSTAKA}

Arafah, 2005. Pengaruh Pemberian Pupuk Organik dan Anorganik terhadp Pertumbuhan dan Hasil Padi Sawah. Jurnal Agrivigor. 4. (2) : 56 - 64.

Janardi, T. 2013. Nitrobacter Solusi Bertani Masa Depan. https://ginte.wordpress.com/2013/04/16/nitrobcter-solusi-bertani-masa-depan/

Mulyadi, A. 2008. Karakteristik Kompos dari Bahan Tanaman Kaliandra, Jerami Padi dan Sampah Sayuran. Program Studi Ilmu tanah, Fakultas Pertanian, Institut Pertanian Bogor. 45 p.

Narka, W. , T. Kusmawati, N. Merit, N. Dibia. 2016. Penerapan Kombinasi Pupuk Organik dan pupuk kimia untuk memperbaiki Kualitas tanah sawah di Subak Tibubiyu Kecamatan Kerambitan, Kabupaten Tabanan (laporan Hibah Udayana Mengabdi)

Santi, T.K. 2006. Pengaruh Pemberian pupuk Kompos terhadap Pertumbuhan tanaman tomat. Jurnal Ilmiah Progressif. 3 ( 9) : 41-49

Sardiana, I K. 2015. Simpanan Karbon Organik, Kualitas Tanah, dan Hasil Caisin (Brassica chinensis) pada Pertanian Organik dan Konvensional di Kecamatan Baturiti, Kabupaten Tabanan, Bali (Disertasi). Program Pasca sarjana Universitas Udayana Denpasar.

Suriadikarta, D.A dan D. Setyorini. 2005. Laporan Hasil Penelitian Standar Mutu Pupuk Organic. Balai Penelitian Tanah Bogor.

Yuniwati. 2012. Optimasi Kondisi Proses Pembuatan Kompos dari Sampah Organik dengan Cara Fermentasi Menggunakan EM4. Jurnal Teknologi. 5 (2) : 172 - 181

VOLUME 17 NOMOR 1, JANUARI 2018 | 159 